\title{
Prey bacteria shape the community structure of their predators
}

\author{
Huan Chen ${ }^{1}$, Rana Athar ${ }^{*}$, Guili Zheng ${ }^{2}$ and Henry N Williams ${ }^{1}$ \\ ${ }^{1}$ Environmental Sciences Institute, Florida A\&M University, Tallahassee, FL, USA and ${ }^{2}$ Department of \\ Epidemiology, University of California at Los Angeles, Los Angeles, CA, USA
}

\begin{abstract}
Although predator-prey interactions among higher organisms have been studied extensively, only few examples are known for microbes other than protists and viruses. Among the bacteria, the most studied obligate predators are the Bdellovibrio and like organisms (BALOs) that prey on many other bacteria. In the macroscopical world, both predator and prey influence the population size of the other's community, and may have a role in selection. However, selective pressures among prey and predatory bacteria have been rarely investigated. In this study, Bacteriovorax, a predator within the group of BALOs, in environmental waters were fed two prey bacteria, Vibrio vulnificus and Vibrio parahaemolyticus. The two prey species yielded distinct Bacteriovorax populations, evidence that selective pressures shaped the predator community and diversity. The results of laboratory experiments confirmed the differential predation of Bacteriovorax phylotypes on the two bacteria species. Not only did Bacteriovorax Cluster IX exhibit the versatility to be the exclusive efficient predator on Vibrio vulnificus, thereby, behaving as a specialist, but was also able to prey with similar efficiency on Vibrio parahaemolyticus, indicative of a generalist. Therefore, we proposed a designation of versatilist for this predator. This initiative should provide a basis for further efforts to characterize the predatory patterns of bacterial predators. The results of this study have revealed impacts of the prey on Bacteriovorax predation and in structuring the predator community, and advanced understanding of predation behavior in the microbial world.
\end{abstract}

The ISME Journal (2011) 5, 1314-1322; doi:10.1038/ismej.2011.4; published online 17 February 2011

Subject Category: microbe-microbe and microbe-host interactions

Keywords: Bdellovibrio and like organisms (BALOs); predator-prey interaction; Vibrio spp.;

Bacteriovorax, microbial community structure

\section{Introduction}

Predation has been studied extensively among animals (Sinclair et al., 2003; Finke and Denno, 2004); however, in the microbial world it has not been well investigated (Jurkevitch, 2007). Of the microorganisms, viral and protistan predation have received greatest attention (Wildschutte et al., 2004; Jurkevitch, 2007; Danovaro et al., 2008). Among the obligate predatory bacteria, the most studied are several genera known collectively as the Bdellovibrio and like organisms (BALOs), which prey on many Gram negative bacteria (Guerrero et al., 1986; Schoeffield and Williams, 1990; Jurkevitch et al., 2000). Contrary to the higher forms where predation and multiplication are not directly linked, the bacterial prey for the BALOs not only serves as a food source but also a growth and multiplication

Correspondence: HN Williams, Florida A\& M University, 1515 S Martin Luther King, Jr Blvd, Tallahassee, FL 32307, USA.

E-mail: henryneal.williams@famu.edu

Deceased.

Received 26 August 2010; revised 13 December 2010; accepted 19 December 2010; published online 17 February 2011 chamber. The predatory cycle of BALOs is unique in being biphasic with an extracellular 'hunt' phase, in which the organisms search for and attack its prey, and an intracellular phase. The latter phase begins when, following attack, the predator penetrates through the prey cell's outer membrane into its periplasmic space where it grows, multiplies and lyses the prey (Rendulic et al., 2004) (Figure 1).

The Bacteriovorax are in the BALO group and are ubiquitous in salt-water environments (Pineiro et al., 2008). As obligate predators, the growth of wild-type Bacteriovorax and other BALOs requires co-cultivation with a prey bacterium, which negates their characterization by the many cultural methods that demand pure cultures. Therefore, few methods are available for distinguishing between BALO isolates. One approach, comparative analysis of $16 S$ rRNA sequences, has enabled identification and detection of specific Bacteriovorax phylogenetic clusters or operational taxonomic units (OTUs) within populations (Pineiro et al., 2004). This has made possible geographical distribution studies that have found that some OTUs occur widely and in diverse environments; whereas, others are restricted to certain ecosystems (Pineiro et al., 2007). Such 


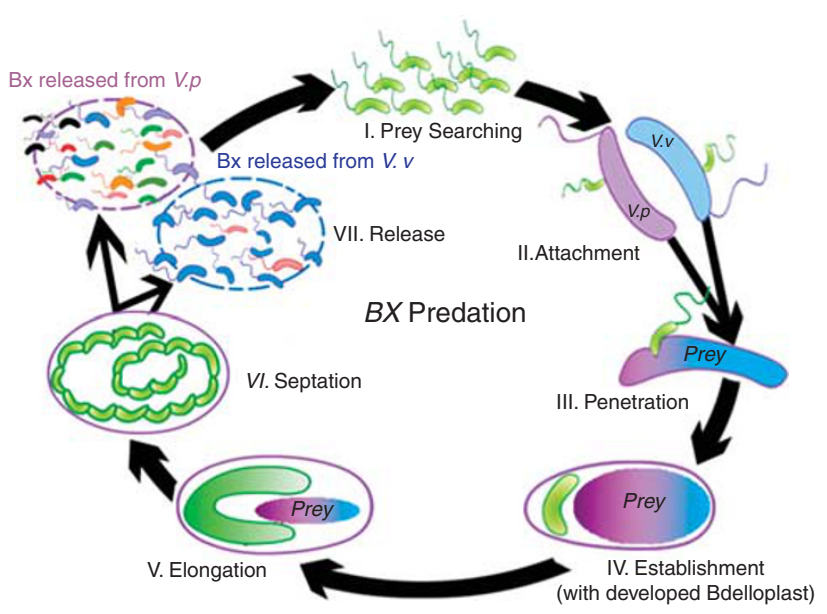

Figure 1 Schematic diagram showing typical Bacteriovorax (Bx) life cycle (I to VII), and the major finding of this study that Bx predation on two preys, $\mathrm{Vp}$ and $\mathrm{Vv}$, yielded two distinct predator communities (VII) consisting of different Bx OTU clusters represented by the different colors, and defined by $16 \mathrm{~S}$ rRNA gene sequences. Step I shows unknown environmental Bx community searching for prey.

findings have advanced knowledge of Bacteriovorax, and raised new questions about environmental parameters that account for the varied distribution patterns of different OTUs. Salinity and temperature are among such parameters (Williams and Falkler, 1984; Pineiro et al., 2007) and there is speculation on a role for the prey (Sutton and Besant, 1994; Pineiro et al., 2004). In this scenario, different prey species select for distinct populations of Bacteriovorax OTUs, and thereby influence the presence, distribution and services of the predators in nature.

Unfortunately, there have been few, if any, investigations on the impact of prey on the shaping of the predator community. Studies have examined the influence of BALO isolates on the bacteria prey community. In one study, in which a single BALO isolate was inoculated into a suspension of several bacterial species, the predator was observed to preferentially prey on certain bacteria (Rogosky et al., 2006). However, to show the influence of any selective pressure of the prey on the selection of predators, requires a corollary study to investigate the response of multiple Bacteriovorax OTUs to a single prey species. No such studies have been reported.

In this study, we describe an investigation on the responses of different native Bacteriovorax OTU populations in environmental water samples to two prey bacteria, Vibrio vulnificus and Vibrio parahaemolyticus. As the two tested prey are of the same genus, we hypothesized that different Bacteriovorax clusters would respond similarly to them, which surprisingly was not found to be the case. The significance of this may have broad implications for the distribution and role of BALOs in bacterial mortality and community structure.

\section{Materials and methods}

Sampling strategy

To test the hypothesis, water samples were collected from sites in three different bodies of water located in Florida (USA): Dry Bar in Apalachicola Bay on three occasions, the eastern coast of the Gulf of Mexico and Atlantic Ocean coastal waters of northern Florida (Supplementary Table 1).

\section{Sampling protocols}

Ten litres of bottom water were retrieved from both sides of a NERR research vessel (25-foot, C-Hawk) using a sterile sampler at a depth of approximately $1.74 \mathrm{~m}$. Physiochemical parameters (temperature, salinity, dissolved oxygen and $\mathrm{pH}$ ) were measured and recorded on site (Supplementary Table 1). Following collections, the samples were stored on ice and transported to the laboratory at Florida A\&M University and cultured for Bacteriovorax. Within $6 \mathrm{~h}$ the samples were used to establish the microcosms described below.

\section{Bacterial strains and growth conditions}

The two bacterial species used as prey were as follows: $V$. vulnificus FLA042 ( $V v)$, a capsulated spontaneous rifampicin-resistant mutant of a virulent environmental strain MLT403, provided by Dr Paul Gulig, University of Florida and $V$. parahaemolytics strain P-5 $(V p)$ obtained from our laboratory stock collection, and is the most widely used prey bacterium for cultivation of Bacteriovorax from salt water systems (Schoeffield and Williams, 1990; Rice et al., 1998; Pineiro et al., 2004). Prey suspensions to establish the enrichment microcosms or for plating for Bacteriovorax recovery, were prepared by adding $5 \mathrm{ml}$ of $70 \%$ artificial sea water (Instant Ocean, Aquarium Systems, Inc., Mentor, OH, USA) (pH 8, salinity 22 p.p.t.) to an overnight culture of either $V_{V}$ grown on Luria-Bertani (LB) culture plates (Difco, Sparks, MD, USA) or $V p$ on sea water yeast extract agar (Kaneko and Colwell, 1973). The colonies were suspended in the liquid and the suspension was transferred into a sterile tube for subsequent use.

\section{Establishment of laboratory microcosms}

Immediately after being transported to the laboratory, water samples were mixed and filtered through a $0.8 \mu \mathrm{m}$ filter (Nalgene, 0974025AA, Rochester, NY, USA) to remove debris and larger organisms, such as some protists. Five hundred $\mathrm{ml}$ of the filtrate was dispensed into each of four 21 Erlenmeyer flasks for the microcosm-enrichment experiments. For subsequent analysis by denaturing gradient gel electrophoresis (DGGE), another $500 \mathrm{ml}$ of the filtrate was filtered through $0.1 \mu \mathrm{m}$ filter (Whatman, 111105, Florham Park, NJ, USA) to capture the microbial populations including Bacteriovorax on the filters, which were stored at $-20^{\circ} \mathrm{C}$. 
To complete the microcosms for the enrichment of Bacteriovorax, suspensions of $V V$ and $V p$ were spiked as prey into the respective flasks, described above to yield an optical density (OD) measurement of 0.7 at $600 \mathrm{~nm}$. This corresponds to approximately $5 \times 10^{8}$ cells $\mathrm{ml}^{-1}$ as enumerated by plate count on LB-rif agar plates (LB agar with $50 \mu \mathrm{g} \mathrm{ml}^{-1}$ rifampicin (Sigma Chemical Co., St Louis, MO, USA)). The two control microcosms established to monitor the OD of the prey without interference from Bacteriovorax or other microorganisms, consisted of equal volumes of prey in sterilized environmental water. The microcosm flasks were shaken at room temperature and monitored at $24 \mathrm{~h}$ intervals through $120 \mathrm{~h}$, by OD measurements (at $600 \mathrm{~nm}$ ) in 48-well microtiter plates by an Absorbance Microplate Reader (Biotek, Winooski, VT, USA).

\section{Quantification of prey bacteria}

The viable prey bacterial counts in the test and control flasks were conducted at selected time points, by spread plating in duplicate $0.1 \mathrm{ml}$ of serial 10-fold diluted samples onto LB-rif or sea water yeast extract agar agar plates for culture of $V_{V}$ and $V p$, respectively. The plates were incubated at $37^{\circ} \mathrm{C}$ for two days, and colony-forming units were counted and recorded.

\section{Isolation of predominant Bacteriovorax strains in microcosms}

Samples from the test microcosms were cultured for Bacteriovorax using the double agar overlay technique (Williams and Falkler, 1984). Before (pre-spike) and immediately $(0 \mathrm{~h})$ after addition of the prey bacteria, $5 \mathrm{ml}$ of sample were inoculated into Pp20 top agar tubes, with $1 \mathrm{ml}$ of prey bacteria $\left(V_{V}\right.$ or $\left.V p\right)$ and plated onto large culture plates $(150 \times 15 \mathrm{~mm})$. At subsequent time points, samples from the test microcosms were diluted by a series of 10 -fold dilutions. One $\mathrm{ml}$ of the dilutions was inoculated into $3.5 \mathrm{ml}$ of molten Pp20 top agar tubes with $500 \mu \mathrm{l}$ of prey. The contents of the tubes were mixed and overlaid onto Pp20 bottom agar plates. The plates were incubated at room temperature for up to 8 days. Randomly selected plaques were examined by fluorescence microscopy for typical Bacteriovoraxlike cells. Plaque-forming units were counted and recorded. Plates with approximately 30 or less plaques were selected for further processing, as these represented the predominant culturable Bacteriovorax OTU within the microcosm at the time of plating. Materials from 80 to $100 \%$ of the plaques on these plates were collected with sterile micropipette tips, and each was inoculated respectively into a $1.5 \mathrm{ml}$ eppendorf tube containing $50 \mu \mathrm{l}$ of autoclaved MiliQ water, and stored at $-20{ }^{\circ} \mathrm{C}$ for subsequent PCR analysis.
PCR amplification and phylogenetic assay

The tubes containing the selected Bacteriovorax plaques were boiled at $100{ }^{\circ} \mathrm{C}$ for $20 \mathrm{~min}$. Ten $\mu \mathrm{l}$ of the suspension was PCR amplified using Bacteriovorax-specific primers, Bac-676F (5'-ATTTCGCATG TAGGGGTA-3') and Bac-1442R (5'-GCCACGGCTTC AGGTAAG-3') (Davidov et al., 2006) by puReTaq Ready-To-Go PCR Beads (GE Healthcare BioSciences, Little Chalfont, UK). All amplifications were performed under the following thermal conditions: initial denaturation at $95{ }^{\circ} \mathrm{C}$ for $3 \mathrm{~min}$, followed by 34 cycles of $96{ }^{\circ} \mathrm{C}$ for $3 \mathrm{~min}$, annealing at $55^{\circ} \mathrm{C}$ for $1 \mathrm{~min}$, extension at $72^{\circ} \mathrm{C}$ for $1 \mathrm{~min}$ and a final extension at $72{ }^{\circ} \mathrm{C}$ for $7 \mathrm{~min}$ in an iCycler thermocycler (Bio-Rad, Hercules, CA, USA). PCR products were analyzed by electrophoresis for amplicons of approximately 760bp, purified with the QIAquick PCR-Purification Kit (Qiagen, Chatsworth, CA, USA) and sequenced with Bac$676 \mathrm{~F}$ primer at the DNA Sequencing Laboratory at Florida State University. DNA sequences and homology searches were analyzed with the Basic Local Alignment Search Tool server, from the National Center of Biotechnology Information (www.ncbi.nlm.nih.gov). Sequences were also analyzed using the Chimera_Check, version 2.7 from the RDP-II Web site (Cole et al., 2003). These sequences have been submitted to the GenBank databases under accession numbers GU350212GU350224.

To compare the diversity of Bacteriovorax clusters with the two preys, Shannon-Weaver index was calculated using Estimates program (http:// viceroy.eeb.uconn.edu/estimates) with 50 randomizations.

Analysis by denaturing gradient gel electrophoresis For DGGE analysis (Muyzer et al., 1993), $20 \mathrm{ml}$ samples were removed from the test microcosm at $24 \mathrm{~h}$ intervals and centrifuged at $11952 \mathrm{~g}$ for $25 \mathrm{~min}$ at $4{ }^{\circ} \mathrm{C}$. The supernatant fluid was discarded and the resulting cell pellet was preserved at $-20^{\circ} \mathrm{C}$. Subsequently, total DNA from the cell pellets and the bacteria previously concentrated on filters from the pre-spiked microcosm water samples were extracted using the QIAGEN Kit (QIAamp DNA Mini Kit), according to the manufacturer's protocol. PCR amplifications were performed with puReTaq Ready-To-Go PCR Beads using universal bacterial primers, GM5F (5'-CCTACGGGAGGCAGCAG-3') with a GC clamp attached to its $5^{\prime}$ end and 907R (5'-CCGTCAATTCCTTTGAGTTT-3') (Muyzer et al., 1995). The amplified DNA was quantified by a NanoDrop Spectrophotometer (ND 1000, Thermo Fisher Scientific, Wilmington, DE, USA), and standardized to an equal concentration. Fifteen $\mu \mathrm{l}$ of PCR products were then run on a $6.5 \%$ polyacrylamide gel with a denaturing gradient of $30-60 \%$. The gel was run in $1 \mathrm{x}$ TAE buffer at $60{ }^{\circ} \mathrm{C}$ and $100 \mathrm{~V}$ for $16 \mathrm{~h}$ on a Dcode Universal 
Mutation Detection System (Bio-Rad), then stained with SYBR green (Molecular probes, Invitrogen, Eugene, OR, USA) for $60 \mathrm{~min}$ and photographed using Geldoc (Bio-Rad). DGGE bands were excised and the DNA was eluted in $50 \mu \mathrm{l}$ of ultrapure Milli-Q water overnight at $4{ }^{\circ} \mathrm{C}$. The eluted DNA was again re-amplified using the universal bacterial primer GM5F and 907R without the GC clamp, and sequenced as previously described.

\section{Electron microscopy of microcosm bacteria}

For electron microscopic studies, $10 \mathrm{ml}$ samples were removed at the $48 \mathrm{~h}$ time point from both $V_{V}$ and $V p$ microcosms and fixed (Koval and Bayer, 1997). Briefly, the cells were centrifuged for $20 \mathrm{~min}$ at $11952 \mathrm{~g}$, resuspended in $1 \mathrm{ml}$ of $0.1 \mathrm{M}$ sodium phosphate buffer ( $\mathrm{pH} 7$ ) and centrifuged for $15 \mathrm{~min}$ at $10600 \mathrm{~g}$. The pellet was resuspended in $2 \mathrm{ml}$ of $0.1 \mathrm{M}$ cacodylate buffer containing $2 \%$ glutaraldehyde and $1 \%$ formaldehyde, both diluted from $25 \%$ $(\mathrm{v} / \mathrm{v})$ and $16 \%(\mathrm{v} / \mathrm{v})$ stock solutions, respectively. After $60 \mathrm{~min}$ at $4{ }^{\circ} \mathrm{C}$ and centrifugation at $10600 \mathrm{~g}$, the pellet was overlaid with cacodylate buffer, and an aliquot of samples was stained with uranyl acetate and examined with a Hitachi H-7600 transmission electron microscope (Hitachi High Technologies, America, Inc., Pleasanton, CA, USA).

\section{Challenging $\mathrm{Vv}$ and $\mathrm{Vp}$ with selected Bacteriovorax} clusters

To confirm the results of the previous microcosm experiments, which suggested that the $V_{V}$ and $V p$ selected for specific Bacteriovorax phylotypes, a laboratory experiment was designed to test the predation efficiency and growth rate of Bacteriovorax Clusters IX and IV against $V_{V}$ and $V p$. Six microcosms were established consisting of four test flasks and two control flasks. Each of the test flasks contained $100 \mathrm{ml}$ sterilized artificial sea water and equal concentrations of either Bacteriovorax Cluster IX or IV (average concentration $1.10 \times 10^{6}$ copies $\mathrm{ml}^{-1}$ ) and prey, $V_{V}$ or $V p$, respectively (average concentration $7.47 \times 10^{7}$ colony-forming units $\mathrm{ml}^{-1}$ ). The same prey concentrations were inoculated into sterilized artificial sea water, as a control to monitor their population excluding the effect of Bacteriovorax predation. Cultures were incubated at $27^{\circ} \mathrm{C}$ on a shaker for $40 \mathrm{~h}$ to monitor the population dynamics between the predator and prey, and their respective abundances at selected time points. The prey in the test and control microcosms were monitored by measurements of OD values every $4 \mathrm{~h}$ and by bacterial plate counts at $0,12,20$ and $40 \mathrm{~h}$.

The Bacteriovorax present in the cultures were enumerated by quantitative real-time PCR (Zheng et al., 2008). Briefly, $1 \mathrm{ml}$ samples were removed at $4 \mathrm{~h}$ intervals and genomic DNA was extracted using the QIAamp DNA Mini kit (Qiagen), with a final product of $100 \mu \mathrm{l}$ eluted. Bacteriovorax-specific primer set, 519F (5'-CAGCAGCCGCGGTAATAC-3') and 677R (5'-CGGATTTTACCCCTACATGC-3') was used for quantification of the Bacteriovorax. Quantitative real-time PCR analysis was performed by using the Bio-Rad CFX96 Real-Time PCR Detection System (Bio-Rad). The quantitative real-time PCR reaction mixtures $(25 \mu \mathrm{l})$ were composed of $12.5 \mu \mathrm{l}$ of iQ SYBR Green Supermix (Bio-Rad), $1 \mu$ l of each primer $\left(5 \mathrm{pmol} \mu \mathrm{l}^{-1}\right), 1 \mu \mathrm{l}$ of sample DNA and $9.5 \mu \mathrm{l}$ of MiliQ water. Thermal cycling conditions were: 2 min at $94^{\circ} \mathrm{C}$, followed by 45 repeats of $30 \mathrm{~s}$ at $94^{\circ} \mathrm{C}$, $10 \mathrm{~s}$ at $62{ }^{\circ} \mathrm{C}$ and $10 \mathrm{~s}$ at $72{ }^{\circ} \mathrm{C}$. Each sample was measured in triplicate and negative controls (no template) were included. A 10-fold dilution series of plasmid containing a fragment of the Bacteriovorax 16S rRNA gene, was used in the quantitative realtime PCR assay to construct the standard curve (correlation coefficient $>0.99$ ).

\section{Statistical analysis}

The abundance of predator and prey (log transformed) was analyzed by analysis of variance to detect significant differences among the numbers of bacteria in the various microcosm treatments. When analysis of variance tests were passed, the HolmSidak test was performed. The T-test was used to compare two groups of treatments when normality and equal variance tests were passed. All statistical analyzes were performed using the Sigmastat, version 3.5, software package.

\section{Results}

Predator-prey interactions in microcosm studies In the five independent experiments with laboratory microcosms, the predator and prey responses exhibited similar patterns (Figure 2). In all cases the inoculated prey, $V_{V}$ or $V p$, decreased with a corresponding increase in Bacteriovorax numbers,

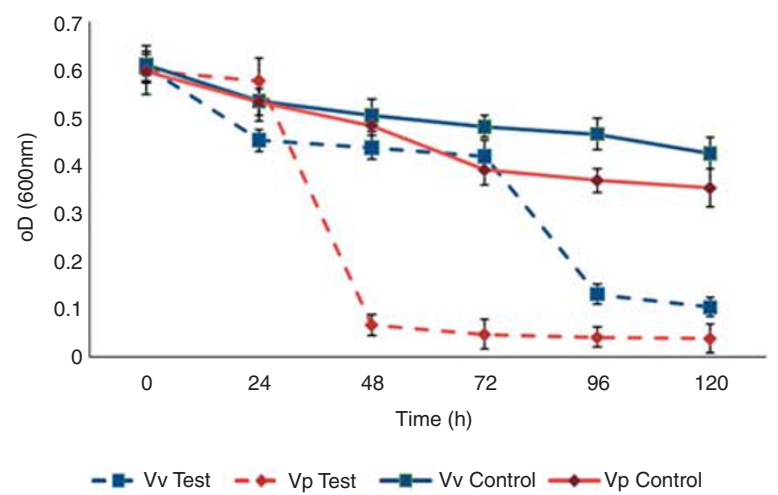

Figure 2 Kinetics of the lysis of $V v$ and $V p$ by Bacteriovorax (Bx) over time in test (with Bx), and control (without Bx) microcosms as measured by optical density. Values are means for the five microcosm experiments. Error bar represents the standard error of the mean $(N=5)$. 


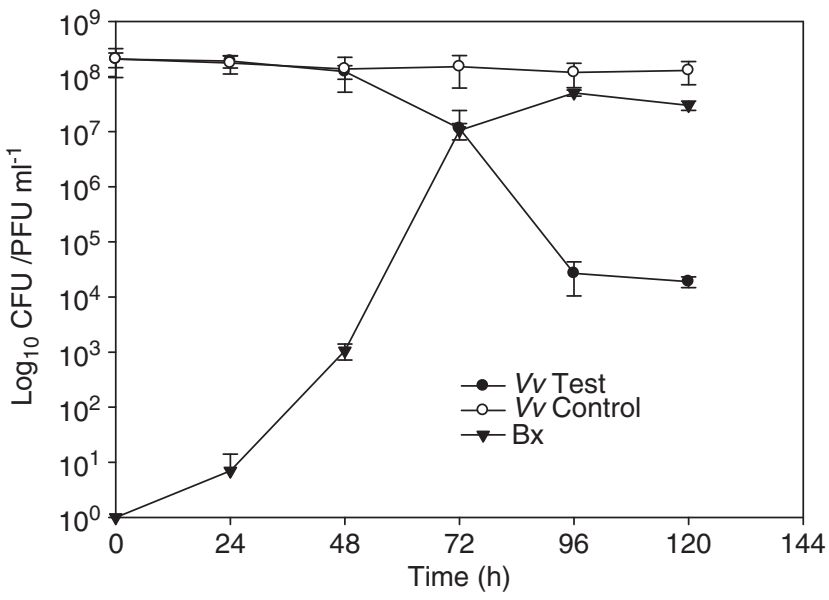

Figure 3 Numbers of $V_{V}$ and Bacteriovorax (Bx) in samples taken at different time intervals from the microcosm established with Atlantic Ocean water, and $V_{V}$ showing the typical predatorprey response, which was observed in all five experiments. The control contained prey cells without Bx. Bars indicate standard error.

indicating the predation of the prey by the predator in the microcosms. The difference between the two prey was that the greatest decrease was observed in the $V p$ microcosms after $24 \mathrm{~h}$, whereas, in the $V_{V}$ microcosms, a significant decrease $(t$-test, $P<0.01)$ was not observed until after $72 \mathrm{~h}$ (Figures 2 and 3 ). The OD measurements of microcosm samples corresponded to the colony-forming units counts of $V_{V}$ on LB-rif agar plates, and $V p$ on the sea water yeast extract agar plates. At the initiation of the microcosm experiments, the Bacteriovorax population that could grow on $V v$ or $V p$ ranged from below detectable levels up to 3 plaque-forming units $5 \mathrm{ml}^{-1}$. However, the predators responded quickly to the inoculated prey resulting in a thousand-fold increase within 24 to $48 \mathrm{~h}$, and typically their numbers peaked at approximately $10^{8}$ plaque-forming units $\mathrm{ml}^{-1}$ at $96 \mathrm{~h}$. This increase in Bacteriovorax resulted in a 2-4 log prey reduction (Figure 3).

Identification of Bacteriovorax 16S rRNA phylogenetic clusters isolated on the two prey

The results revealed that irrespective of the source from which the microcosm water was collected, the predominant Bacteriovorax isolates, recovered on $V V$, typically belonged to Cluster IX and occasionally Cluster X (Figures 4a-e). Only in a single case, isolates of Cluster III were detected (Figure 4d). In the first microcosm experiment with water from Dry Bar, all plaques analyzed growing on $V_{V}$ at the $24 \mathrm{~h}$ sample were of Cluster X. Plaques from the later time points could not be confirmed to be Bacteriovorax (Figure 4a). In the latter four $V V$ microcosm experiments established with waters from Dry Bar, Gulf of Mexico and the Atlantic Ocean, the Bacteriovorax isolates detected throughout the term of the experiment consistently belonged to Clusters IX and X. This was in contrast to the $V p$ microcosms, in which shifts among different Bacter- iovorax clusters from one sampling interval to the next (Figures 4c-e) were frequently observed. Up to six different cluster types were observed over the duration of one experiment (Figure 4d). For the first Dry Bar experiment, the predominant Bacteriovorax detected on $V p$ at all time points were Cluster $\mathrm{V}$ (Figure 4a). Cluster $X$, which was predominant at $24 \mathrm{~h}$ in the $V_{V}$-enriched microcosm, was not found in the $V p$ microcosm (Figure 4a). For the second Dry Bar experiment, all the predominant isolates from both $V_{V}$ and $V p$ microcosms were of Cluster IX (Figure 4b). In the third experiment using Dry Bar waters, all Bacteriovorax isolates from the $V_{V}$ microcosm were Cluster IX, whereas, five Bacteriovorax clusters were recovered from the $V p$ microcosm (Figure 4c). Dramatic shifts in Bacteriovorax clusters detected were also observed in the Gulf of Mexico and ocean water $V p$ microcosms (Figures $4 \mathrm{~d}$ and e). However, Cluster IX, which predominated in

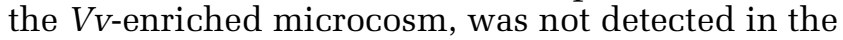
$V p$ ocean microcosm and only once in the Gulf of Mexico microcosm (Figures $4 \mathrm{~d}$ and e). Over the five experiments, a total of eight Bacteriovorax OTUs were detected on the two preys. In $V p$ microcosms the Shannon-Weaver index of Bacteriovorax biodiversity was higher for all the sampling sites than the index for $V_{V}$ microcosms. The lower index indicates that only a few OTUs accounted for most of the Bacteriovorax biomass (Table 1). In Dry Bar \#1 and \#3 $V_{V}$ microcosms, the index value was zero indicating that the Bacteriovorax OTUs detected were all identical.

These results show that the interactions of native environmental Bacteriovorax with $V_{V}$ and $V p$ yielded different Bacteriovorax OTU populations, and suggest that $V_{V}$ is preferential for Cluster IX. This distinct and rather drastic difference in the Bacteriovorax OTU communities from the two prey bacteria was not anticipated.

DGGE analysis of microcosm bacterial communities DGGE targeting the 16S rRNA genes was used to analyze the bacterial community structure in the microcosms at selected time intervals. The prominent bands in the DGGE gel were excised and sequenced to confirm bacterial species composition. The greater the numbers of a particular bacterium in the sample, the more intense its band appears in the gel. Neither $V_{V}$ nor $V p$ was detected by DGGE in the original water sample before establishing the microcosms. After the microcosms were amended with the prey, an intense band was observed. For the $V_{V}$ microcosm, the prey population gradually diminished with time (Supplementary Figure 1 and Figure 2). For the Vp microcosm, the prey band was not detected after 24h (Supplementary Figure 3) confirming that predation on $V p$ was more rapid than observed on $V v$. Meanwhile, in both the $V v$ and $V p$ microcosms, the intensity of the Bacteriovorax band increased with time. The bands representing other 
a

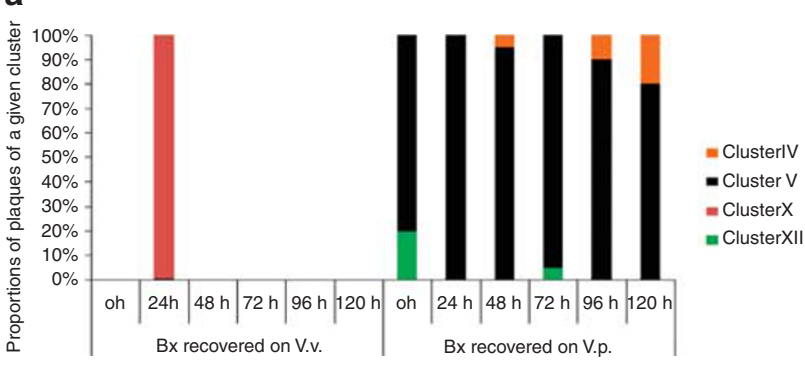

b

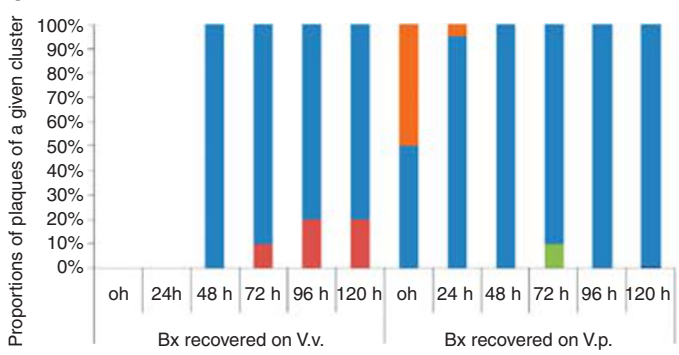

C

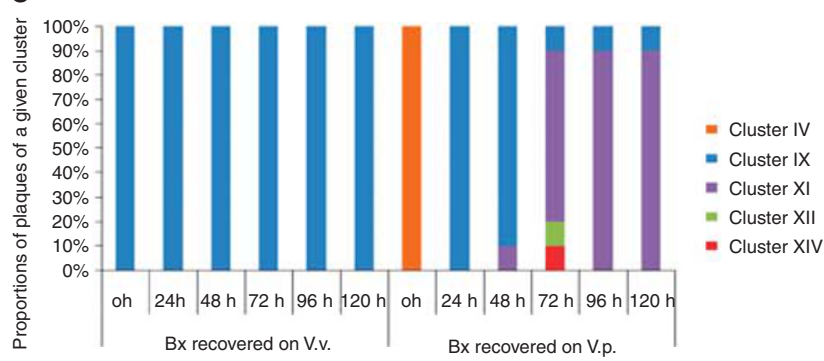

d

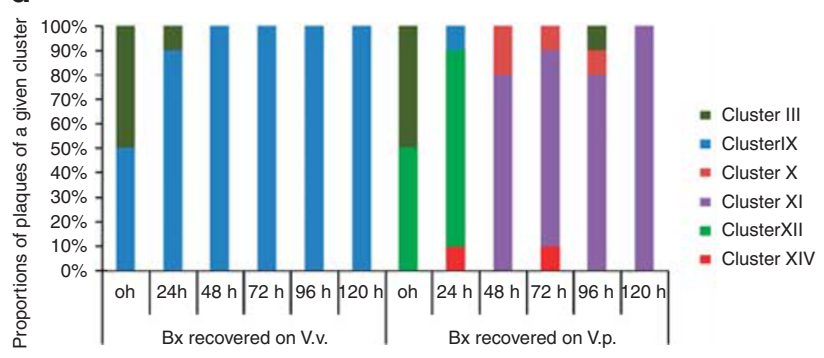

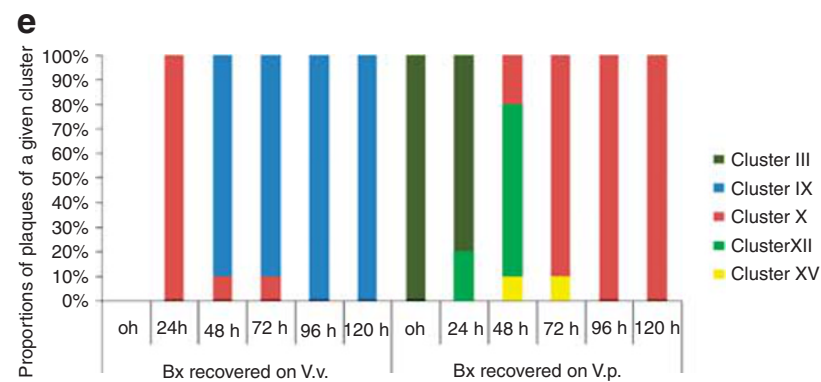

Figure 4 Predominant Bacteriovorax operational taxonomic units recovered at various time intervals from the $V_{V}$ (left) and $V p$ microcosms (right) established with water samples from Dry Bar (a, b and $\mathbf{c}$ ), Gulf of Mexico (d) and Atlantic Ocean (e). Clusters based on 16S rRNA gene sequence similarity are numbered consistently with previous reports (Davidov and Jurkevitch, 2004; Pineiro et al., 2007, 2008).

Table 1 Diversity index of Bacteriovorax in microcosms from different sites using $V_{V}$ and $V p$ as prey

\begin{tabular}{lcc}
\hline \multirow{2}{*}{ Sites } & \multicolumn{2}{c}{ Shannon-Weaver index } \\
\cline { 2 - 3 } & $V_{V}$ & $V p$ \\
\hline Dry Bar \#1 & 0 & \multirow{2}{*}{0.41} \\
Dry Bar \#2 & 0.08 & 0.37 \\
Dry Bar \#3 & 0 & 1.16 \\
Gulf of Mexico & 0.32 & 1.18 \\
Atlantic Ocean & 0.55 & 1.1 \\
\hline
\end{tabular}

major bacteria present in the $V_{V}$ microcosm at the initial time point, either disappeared or in some cases increased in intensity (Supplementary Figure 1). The predominant Bacteriovorax OTUs shown by DGGE analyses were consistent with the results from the culture methods (Figure 4, Supplementary Figures 1, 2 and 3).

\section{Electron microscopic examination of microcosm samples}

Examination of $V_{V}$ and $V p$ microcosm samples, respectively, by transmission electron microscopy revealed the attachment of Bacteriovorax cells to both the preys (Supplementary Figure 4), and the predator inside prey cells forming the bdelloplast. These observations are further confirmation of predation. Observing that the $V_{V}$ cells are longer but smaller in width than the $V p$ cells, raises the question of the impact of prey size on observed differences in Bacteriovorax OTU predation on the two preys.

Challenge of $\mathrm{Vv}$ and $\mathrm{Vp}$ with selected Bacteriovorax clusters

When Bacteriovorax Clusters IV and IX were, respectively, inoculated into independent cultures of $V_{V}$ and $V p$, each was able to reduce the abundance of the two preys as measured by plate count and OD readings, confirming the potential of Bacteriovorax to control both the preys. The reductions in plate counts were significant (analysis of variance, $P<0.001$, Holm-Sidak, $P<0.001$ ) at $40 \mathrm{~h}$ for all treatments. The abundance of $V_{V}$ and $V p$ in the control microcosms remained stable (not significantly different, analysis of variance, $P>0.5$ ). 
1320
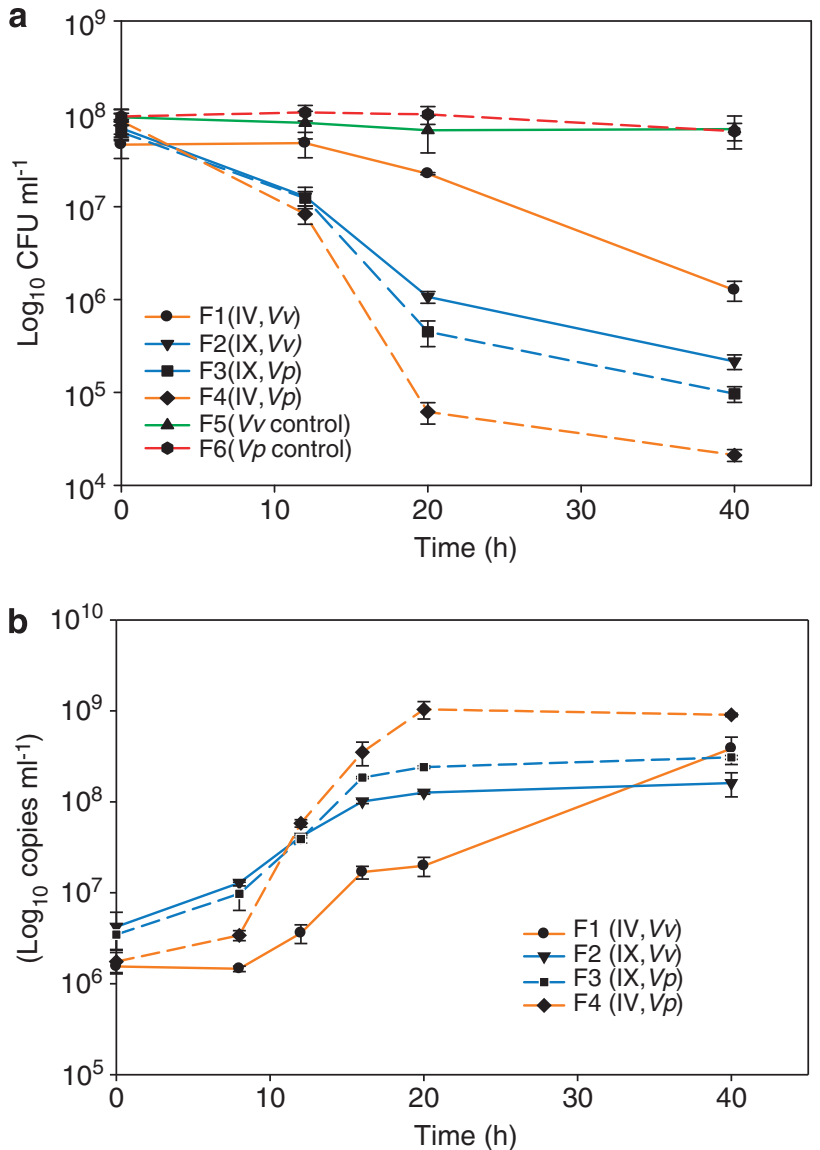

Figure 5 Kinetics of the lysis of $V_{V}$ and $V p$ by Bacteriovorax (Bx) predation and the growth of bx on these prey. Bx microcosm flasks designated F1 and F2 contained $V_{V}$ and Bx Clusters IV and IX, respectively. F3 and F4 consisted of $V p$ as prey and the respective Bx Clusters IX and IV. F5 and F6 represent the control microcosms consisting solely of $V V$ or $V p$ respectively without the interference of any predator. (a) Prey counts showing the effects of Bx Clusters IX and IV on population dynamics of $V V$ or $V p$ in experimental microcosms. (b) Growth dynamics of Bx Clusters IV and IX on $V_{V}$ and $V p$ over a $40 \mathrm{~h}$ period as measured by QPCR assay. Values are means for triplicate samples. Error bars represent the standard deviation of the mean $(N=3)$.

Both the killing of prey and growth rates of Cluster IV against $V p$ were significantly higher than that against $V v$, in the first $20 \mathrm{~h}$ of incubation ( $t$-test, $P<0.01)$. At the 20-h time point, Cluster IV reduced the $V p$ by 3.13 logs, but the $V v$ by only 0.31 logs. After 20-h incubation, Cluster IV abundance in the $V p$ microcosm levelled off reaching about $9.1 \times 10^{8}$ copies $\mathrm{ml}^{-1}$, and the killing rate decreased from 0.12 per hour at maximum to 0.03 per hour because of the low number of remaining prey. In contrast, the predation rate of Bacteriovorax Cluster IX was not significantly impacted by the type of prey in the first $12 \mathrm{~h}$ ( $t$-test, $P=0.837$ ). Cluster IX reduced the $V V$ cells 2.5 logs after $40 \mathrm{~h}$, whereas Cluster IV reduced them by only 1.5 logs (Figure $5 \mathrm{a}$ ). Corresponding to the decrease in prey, Bacteriovorax Cluster IX grew at a much faster rate on $V_{V}$ than Cluster IV in the first $8 \mathrm{~h}$ of the experiment ( $t$-test, $P<0.01$ ), whereas no such difference was observed on $V p$ (Figure 5b).

\section{Discussion}

The results of this study reveal new insights into the responses of native environmental Bacteriovorax communities to different bacterial species. For the first time it has been shown that specific Bacteriovorax OTUs vary in their predation on different bacteria, likely due to selective pressures exerted by the prey that yield predator progeny populations that vary in strain richness and composition. This was demonstrated in the responses of native Bacteriovorax populations in water samples collected from different ecosystems to two Vibrio species, and showed that the interaction of Bacteriovorax to specific prey is not random. With a single exception, only two phylotype Clusters, IX and X, were consistently observed to be the predominant Bacteriovorax OTU produced in $V_{V}$. To the contrary, multiple clusters were typically detected from $V p$. This observation was consistent over multiple experiments conducted in three different water bodies, and was confirmed in a laboratory experiment using selected Bacteriovorax isolates in dual culture with the two preys. These findings were surprising as we had expected no difference in the specific Bacteriovorax clusters grown on the two Vibrio species, as they are closely related, being in the same genus. This establishes Clusters IX and $\mathrm{X}$ as keystone predators of $V_{V}$.

Although the specific reasons for the observed differential predation were not definitively determined, electron microscopic examination of the predator-prey interactions revealed the $V_{V}$ to be considerably smaller in width than the $V p$ cells. Prey size has been reported to be a factor in predation for some microbes (Pernthaler, 2005). The small size of the $V_{V}$ may exclude some Bacteriovorax. However, unique properties of Bacteriovorax Clusters IX and X, which allow them to overcome the prey exclusion, may explain the differential predation efficiency on the two preys but further investigation is needed. Preferential predation of BALOs on certain bacteria species has been reported (Rogosky et al., 2006); however, no known selective mechanisms such as receptor sites or chemotaxis toward a specific prey have been identified.

Another distinction observed between the responses of the Bacteriovorax in the $V_{V}$ and $V p$ microcosms during the 5-day period of the experiment was the stability of the predator population. For the $V_{V}$ microcosms, typically the predominant Bacteriovorax cluster type observed initially at $24 \mathrm{~h}$ remained relatively stable throughout the duration of the experiments. This was in contrast to the $V p$ microcosms, in which shifts in the predominant Bacteriovorax cluster populations were observed with up to six phylotype clusters in one experiment (Figure 4d). The reasons for the shifts in the $V p$ microcosms are not known, but may be because of differences in growth rate over time among the various cluster types, which we confirmed in the laboratory experiment. 
When the predation behaviors of BALO clusters from our study are considered in the context of the conventional classification scheme of parasitoid or predators (Symondson et al., 2003), we found that Cluster IX possesses some of the properties of both generalist, which preys upon a broad range of prey, and specialist which typically have unique properties to prey upon a narrow spectrum of prey. However, until now there has been no evidence to categorize the BALOs in this scheme. The observation that Cluster IX not only has the versatility to be the exclusive efficient predator on $V V$, thereby, behaving as a specialist, but is also able to prey with similar efficiency on $V p$ (Figure 5), is indicative of a generalist. Thus we propose, based on its behavior pattern, that an appropriate designation for Cluster IX is that of a versatilist. The advantage of being a versatilist is apparent, it can prey efficiently on bacteria that other predators typically cannot, thereby, minimizing competition, yet its predation is not restricted to just a single prey.

Although Cluster IX can prey on $V p$ as does Cluster IV, it is less efficient. This reduced efficiency in predation may be a cost to Cluster IX for the benefits it gained as a versatilist. This explains our observation in the ecological studies. When fed the selective prey ( $V_{V}$ narrower), versatilist had the advantage to predominate the predator community, whereas with non-selective prey such as $V p$, they competed with other Bacteriovorax clusters resulting in shifts among the predators. Which cluster predominates may be determined by the number and type of the prey present at that time.

If we assume that the selective pressure exerted by the $V_{V}$ prey is its small width making it difficult for BALOs to enter into the cell, then it could be expected that when Cluster IX predator encounters $V p$ not having the width restriction it would prey with equal efficiency as cluster IV. However, this was not observed to be the case. Although speculative, this may suggest that in its adaptation to prey on $V v$, cluster IX was altered in some way that made it less efficient at preying on other prey. The adaptation made by $V_{V}$ to resist predation by most BALO predators and the counter adaptation of cluster IX to prey on it at relatively high efficiency are very specific events. For two such highly specific and coordinated events to have occurred in two different organisms, raises the possibility of co-evolution.

The superiority of $V$. parahaemolyticus strains in quantitatively recovering Bacteriovorax, has made it the most widely used prey bacterium for cultivation of the predators from salt waters systems (Schoeffield and Williams, 1990; Rice et al., 1998; Pineiro et al., 2004). However, until now the question as to if $V$. parahaemolyticus or any other bacterium is capable of capturing the total population of the Bacteriovorax community in the environment has remained unanswered. The results from our study show that not all of the Bacteriovorax clusters were detected on either $V p$ or $V v$. This reveals the limitations of prey bacteria in recovering with equal efficiency all BALO OTU's.

Although the significance of Bacteriovorax community structure and diversity is only beginning to be recognized (Chauhan et al., 2009), in general, biodiversity has been reported to be an important factor in ecosystem function and responses to environmental changes (Bell et al., 2005; Fuhrman, 2009). Regarding services of BALO populations in the environment, diversity is likely an important factor, especially relative to their potential function in controlling and shaping bacterial communities through selective mortality, which may be dependent upon the specific predator OTUs present. This hypothesis is consistent with the observation in this and other studies (Davidov et al., 2006; Rogosky et al., 2006) that not all Bacteriovorax OTUs are equal in their ability to prey on various bacteria. For example, based on the results reported here, the presence of Clusters IX and X in an environmental niche would be expected to be more important factors, than other clusters in contributing to the mortality of $V_{V}$ populations in that situation.

The results of this study have revealed important features, not previously described, of the significance of the prey on Bacteriovorax predation and in structuring the predator community. Based on these results, the classification of BALO predators using the conventional classification scheme has been initiated and should provide a basis for further efforts to advance this area. It is of interest to determine in future studies which of these classifications, generalist, specialist or versatilist will prevail with other prey bacteria. Understanding BALO-prey interactions will lead to a greater comprehension and appreciation for the diversity of predation among all organisms.

\section{Acknowledgements}

This work was financially supported by grants from the United States Department of Agriculture CSREES (FLAX0715709) and the National Science Foundation under Grant Number (0531523). We thank Dr Paul Gulig at University of Florida and Drs Ashvini Chauhan and Richard Gragg for their input; Megan Lamb at Apalachicola Bay, National Estuarine Research Reserve for research vessel operation and the assistance of Drs Jill W Verlander and Sharon W Matthews at the University of Florida College of Medicine Electron Microscopy Facility.

\section{References}

Bell T, Newman J, Silverman B, Turner S, Lilley A. (2005). The contribution of species richness and composition to bacterial services. Nature 436: 1157-1160.

Chauhan A, Cherrier J, Williams H. (2009). Impact of sideways and bottom-up control factors on bacterial 
community succession over a tidal cycle. Proc of the Natl Acad of Sci 106: 4301.

Cole J, Chai B, Marsh T, Farris R, Wang Q, Kulam S et al. (2003). The ribosomal database project (RDP-II): previewing a new autoaligner that allows regular updates and the new prokaryotic taxonomy. Nucleic Acids Res 31: 442.

Danovaro R, Dell'Anno A, Corinaldesi C, Magagnini M, Noble R, Tamburini C et al. (2008). Major viral impact on the functioning of benthic deep-sea ecosystems. Nature 454: 1084-1087.

Davidov Y, Friedjung A, Jurkevitch E. (2006). Structure analysis of a soil community of predatory bacteria using culture-dependent and culture-independent methods reveals a hitherto undetected diversity of Bdellovibrio-and-like organisms. Environ Microbiol 8: 1667-1673.

Davidov Y, Jurkevitch E. (2004). Diversity and evolution of Bdellovibrio-and-like organisms (BALOs), reclassification of Bacteriovorax starrii as Peredibacter starrii gen. nov., comb. nov., and description of the BacteriovoraxPeredibacter clade as Bacteriovoracaceae fam. nov. Int J Syst Evol Microbiol 54: 1439-1452.

Finke D, Denno R. (2004). Predator diversity dampens trophic cascades. Nature 429: 407-410.

Fuhrman JA. (2009). Microbial community structure and its functional implications. Nature 459: 193-199.

Guerrero R, Pedros-Alio C, Esteve I, Mas J, Chase D, Margulis L. (1986). Predatory prokaryotes: predation and primary consumption evolved in bacteria. Proc Natl Acad Sci USA 83: 2138-2142.

Jurkevitch E. (2007). Predatory Prokaryotes: Biology, Ecology and Evolution. Springer Verlag: Berlin Heidelberg New York.

Jurkevitch E, Minz D, Ramati B, Barel G. (2000). Prey range characterization, ribotyping, and diversity of soil and rhizosphere Bdellovibrio spp. isolated on phytopathogenic bacteria. Appl Environ Microbiol 66: 2365-2371.

Kaneko T, Colwell R. (1973). Ecology of Vibrio parahaemolyticus in Chesapeake Bay. J Bacteriol 113: 24.

Koval SF, Bayer ME. (1997). Bacterial capsules: no barrier against Bdellovibrio. Microbiology 143(Part 3): 749-753.

Muyzer G, de Waal E, Uitterlinden A. (1993). Profiling of complex microbial populations by denaturing gradient gel electrophoresis analysis of polymerase chain reaction-amplified genes coding for 16S rRNA. Appl Environ Microbiol 59: 695.

Muyzer G, Teske A, Wirsen C, Jannasch H. (1995). Phylogenetic relationships ofThiomicrospira species and their identification in deep-sea hydrothermal vent samples by denaturing gradient gel electrophoresis of 16S rDNA fragments. Arch Microbiol 164: 165-172.
Pernthaler J. (2005). Predation on prokaryotes in the water column and its ecological implications. Nat Rev Microbiol 3: 537-546.

Pineiro SA, Sahaniuk GE, Romberg E, Williams HN. (2004). Predation pattern and phylogenetic analysis of Bdellovibrionaceae from the Great Salt Lake, Utah. Curr Microbiol 48: 113-117.

Pineiro SA, Stine OC, Chauhan A, Steyert SR, Smith R, Williams HN. (2007). Global survey of diversity among environmental saltwater Bacteriovoracaceae. Environ Microbiol 9: 2441-2450.

Pineiro SA, Williams HN, Stine OC. (2008). Phylogenetic relationships amongst the saltwater members of the genus Bacteriovorax using rpoB sequences and reclassification of Bacteriovorax stolpii as Bacteriolyticum stolpii gen. nov., comb. nov. Int J Syst Evol Microbiol 58: 1203-1209.

Rendulic S, Jagtap P, Rosinus A, Eppinger M, Baar C, Lanz C et al. (2004). A predator unmasked: life cycle of Bdellovibrio bacteriovorus from a genomic perspective. Science 303: 689-692.

Rice TD, Williams HN, Turng BF. (1998). Susceptibility of bacteria in estuarine environments to autochthonous Bdellovibrios. Microb Ecol 35: 256-264.

Rogosky AM, Moak PL, Emmert EA. (2006). Differential predation by Bdellovibrio bacteriovorus 109J. Curr Microbiol 52: 81-85.

Schoeffield AJ, Williams HN. (1990). Efficiencies of recovery of bdellovibrios from brackish-water environments by using various bacterial species as prey. Appl Environ Microbiol 56: 230-236.

Sinclair A, Mduma S, Brashares J. (2003). Patterns of predation in a diverse predator prey system. Nature 425: 288-290.

Sutton D, Besant P. (1994). Ecology and characteristics of bdellovibrios from three tropical marine habitats. Mar Biol 119: 313-320.

Symondson W, Sunderland K, Greenstone M. (2003). Can generalist predators be effective biocontrol agents? 1. Ann Rev of Entomol 47: 561.

Wildschutte H, Wolfe DM, Tamewitz A, Lawrence JG. (2004). Protozoan predation, diversifying selection, and the evolution of antigenic diversity in Salmonella. Proc Natl Acad Sci USA 101: 10644-10649.

Williams HN, Falkler Jr WA. (1984). Distribution of bdellovibrios in the water column of an estuary. Can J Microbiol 30: 971-974.

Zheng G, Wang C, Williams HN, Pineiro SA. (2008). Development and evaluation of a quantitative real-time PCR assay for the detection of saltwater Bacteriovorax. Environ Microbiol 10: 2515-2526.

Supplementary Information accompanies the paper on The ISME Journal website (http://www.nature.com/ismej) 